\title{
0736. Role of CAMP in PAF-induced intestinal endo-and epithelial dysfunction
}

\author{
I Lautenschläger ${ }^{1 *}$, K Zitta $^{1}$, J Sarau ${ }^{1,2}$, H Dombrowsky ${ }^{1,2}$, YL Wong ${ }^{1}$, M Albrecht $^{1}$, S Uhlig ${ }^{3}$, I Frerichs ${ }^{1}$, N Weiler ${ }^{1}$ \\ From ESICM LIVES 2014 \\ Barcelona, Spain. 27 September - 1 October 2014
}

\section{Introduction}

Platelet activating factor (PAF) induces vascular barrier breakdown and intestinal failure that contribute to the development of sepsis. The exact cellular mechanisms are not well understood.

\section{Objectives}

We aim to analyse the role of cAMP in PAF-induced intestinal endo- and epithelial dysfunction.

\section{Methods}

An isolated model of the rat small bowel (1) was used. Intestines were stimulated with a $0.5 \mathrm{nmol}$ PAF bolus via the mesenteric artery alone (PAF, $\mathrm{n}=5$ ) or after pretreatment with IBMX $(100 \mu \mathrm{M})$ and forskolin $(0.5 \mu \mathrm{M})$ for 20 min $(\mathrm{PAF}+\mathrm{PDE} / \mathrm{AC}, \mathrm{n}=4)$ to increase intracellular cAMP by inhibition of phosphodiesterase (PDE) and stimulation of adenylate cyclase (AC). The pressure responses, the vascular fluid loss and the transfer of FITC-labeled vascular dextran were monitored. cAMP was measured in PAF stimulated and untreated intestines $(n=5) 3$ min after PAF-stimulation or at the equivalent time point.

\section{Results}

The maximal pressure amplitude ( $\Delta \mathrm{Pmax})$, the time delay to achieve $\Delta P \max (\operatorname{td} \Delta \mathrm{Pmax})$, the vascular volume loss (Vloss) as well as the macromolecule transfer to the lymph (FITClym) and to the lumen (FITClum) were reduced significantly by inibition of PDE and stimulation of AC [Table 1].

\section{Conclusions}

While drugs that increase the intracellular cAMP concentration protect the intestine from PAF-induced endo- and
Table 1

\begin{tabular}{llll}
\hline & PAF & PAF+PDE/AC & \\
\hline$\Delta$ Pmax $(\mathrm{mmHg})$ & $30.2 \pm 4.0$ & $14.7 \pm 1.4$ & $\mathrm{p}<0.05$ \\
\hline td $\Delta$ Pmax $(\mathrm{min})$ & $1.45 \pm 0.15$ & $0.77 \pm 0.11$ & $\mathrm{p}<0.05$ \\
\hline Vloss $(\mathrm{ml})$ & $19.2 \pm 5.7$ & $3.6 \pm 0.7$ & $\mathrm{p}<0.05$ \\
\hline FITClym $\left(\mathrm{mg} / 15 \mathrm{~min} / \mathrm{g}^{\Psi}\right)$ & $0.407 \pm 0.078$ & $0.026 \pm 0.011$ & $\mathrm{p}<0.05$ \\
\hline FITClum $\left(\mathrm{mg} / 15 \mathrm{~min} / \mathrm{g}^{\Psi}\right)$ & $0.671 \pm 0.169$ & $0.013 \pm 0.010$ & $\mathrm{p}<0.05$ \\
\hline$\Psi$ dry weight & & &
\end{tabular}

CAMP levels in control and PAF treated intestines were comparable (CAMPCON $4.99 \pm 1.76 \mathrm{nM}$ vs CAMPPAF $4.98 \pm 0.88 \mathrm{nM}, \mathrm{p}>0.1$ ).

epithelial dysfunction, all the cellular effects of PAF can not be explained by a deprivation of cAMP in the intestine.

\section{Authors' details}

${ }^{1}$ University Medical Centre Schleswig-Holstein, Dept. Anaesthesiology and Intensive Care Medicine, Kiel, Germany. ${ }^{2}$ Leibniz Centre for Medicine and Biosciences, Priority Area Asthma and Allergies, Borstel, Germany. ${ }^{3}$ RWTH, Dept. of Pharmacology and Toxicology, Aachen, Germany.

Published: 26 September 2014

\section{Reference}

1. Lautenschläger, et al: Am J Physiol Gastrointest Liver Physiol 2010, 298 : G304-313.

doi:10.1186/2197-425X-2-S1-P58

Cite this article as: Lautenschläger et al:: 0736. Role of CAMP in PAFinduced intestinal endo-and epithelial dysfunction. Intensive Care Medicine Experimental 2014 2(Suppl 1):P58. 